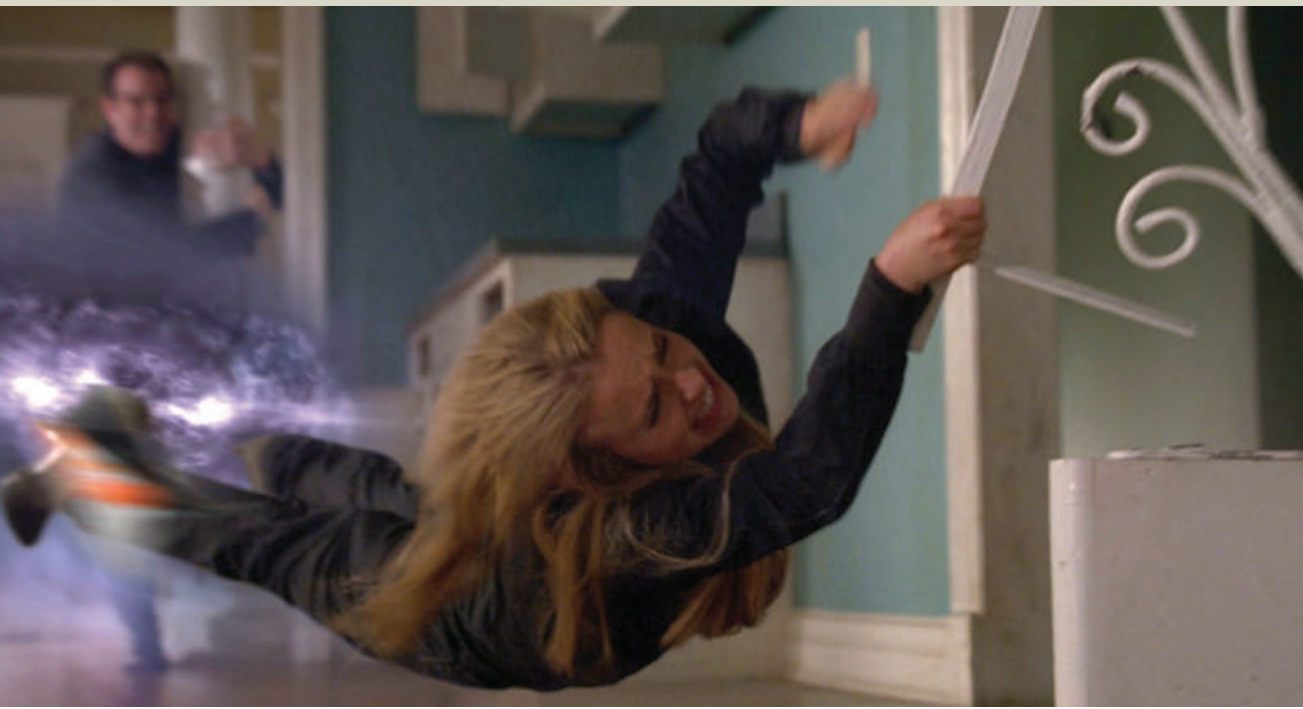

Many of the 'superpowers' portrayed in the television series Heroes are no longer science fiction.

but misplaced essay on 'evidence dolls', the creation of designers Anthony Dunne and Fiona Raby. The plastic miniatures are a hypothetical future product in which to store sperm and hair samples of prospective reproductive partners. The dolls are personified by four women, who reveal how knowledge of their partner's genes might influence their sexual and reproductive lifestyles.

Two other essays that centre on human enhancements - such as the lower-leg prostheses that allow South African runner Oscar Pistorius to compete with able-bodied athletes - are left to later sections. This misfiling of the book's content makes its arguments and themes hard to follow. Sociologist Steve Fuller's history of humans playing God is a thoughtful reminder of how badly we have handled aspects of divinity in the past, but it belongs nearer to Pramod Nayar's narrative on post-human rights. Both essays grapple with the prospect of endowing legal and moral status to our cybernetic or genetically enhanced descendants.

The book's over-designed layout - a hybrid of uber-stylish photography mixed with elements of the record sleeve from Radiohead's seminal album OK Computer - does not aid the reader experience. Indeed, the voice of musicians is absent, which weakens the book's proclamations of diversity.

The Science of Heroes explores similar themes, but in a very different style. It uses the vehicle of Heroes, the popular sci-fi television series that follows the moral chaos inflicted on a clutch of people who have incredible powers proportional to their youth and good looks. In the book, Yvonne Carts-Powell propels the reader on an enthusiastic and entertaining journey through the realms of biology and physics that might one day produce the first genuine super people.

And that day might come sooner than we think. The regenerative powers of Heroes character Claire are ones we already possess we are just slower to heal. Hiro's teleportation has been achieved, at least in the subatomic world, and metamaterials with negative refractive indexes promise invisibility for all. Other powers, such as the ability to steal memory, are already with us in the form of drugs that help victims of trauma to forget.

Historically, superheroes are a snapshot of the relationship between science and society at any one time, based on their powers and how they obtained them. From the perfect
Superman born of a 1930s United States adopting eugenic practices, to the nuclearpowered Spider-Man of the cold-war era and the psychologically disturbed Batman incarnations of the therapy-obsessed 1980s and 1990s, every generation has its super people. Those portrayed in Heroes are the genetically enhanced Generation X of the superhero world - too busy to save the world because their own lives are in perpetual turmoil.

Societies get the superheroes they need most. Human Futures and The Science of Heroes give a tantalizing glimpse of how science might make this a reality in a future human existence. And given Carts-Powell's talent for explaining the science, perhaps an army of her clones will take over high-school education.

Arran Frood is a science writer based in the United Kingdom.

e-mail: arranfrood@gmail.com

\title{
Is there life on Europa?
}

\author{
Unmasking Europa: \\ The Search for Life on Jupiter's Ocean Moon \\ by Richard Greenberg \\ Praxis/Springer: 2008. 278 pp \\ $€ 17.50 / \$ 27.50$
}

In the field of astrobiology, the discovery of life beyond Earth sits like a gem inside the nested Russian dolls of physics, geology, chemistry and, ultimately, biology. Efforts to understand the habitability of worlds within our Solar System began with physical and astronomical surveys, and have now moved on to the challenge of cracking open the geological secrets of key destinations such as Mars and the large, icy moons of Jupiter and Saturn.

Understanding the geological context for life is critical. Rock cycles, whether they are of silicates or ices, enable chemical cycles that can then be exploited by biological systems. Such cycles are central to life on Earth. On Mars, the demise of mantle convection may have led to the planet becoming cold and dry. Near the giant planets of the outer Solar System, and perhaps around massive extrasolar planets, rock cycles may be driven by the gravitational squeezing of icy moons due to tidal interactions. On icy moons such as Jupiter's Europa, the mixing of irradiated, oxidant-rich surface ice with a water ocean could maintain a chemically rich environment capable of sustaining life.

In Unmasking Europa, planetary scientist Richard Greenberg details in depth our geological understanding of the tidally tormented icy surface of Europa. Without pulling any punches, he also describes the equally tormented scientific debate that has led to the current canon. More than a decade after the Galileo spacecraft returned magnetic-field and gravity data that strengthened the case for a subsurface, liquid-water ocean on Europa, we still do not know whether that ocean lies beneath an ice shell just a few kilometres thick or a shell with a thickness of more than ten kilometres.

From an astrobiology perspective, a thin shell could permit direct cycling of oxidant-rich ices with the ocean. A thick ice shell, however, would impede the cycling of surface material, possibly limiting the chemical energy available to any life below the surface. On this contentious debate over the ice thickness, Greenberg notes, "by itself, modelling of heat transport on Europa is too uncertain to definitively discriminate between thin conductive or thick convective ice". However, on the basis of a host of geological features observed in images from the Voyager and Galileo missions, many of which are reproduced in the book, Greenberg argues compellingly that only a thin shell is consistent with the observed ridges, cycloidal features and chaotic terrain of Europa, all of which can be explained through tidal dynamics.

Although Greenberg occasionally strikes an acerbic tone when describing scientific differences with those on what he calls the thickice bandwagon, his motivation seems noble. He fears that "the most brilliant young minds 
may leave science if they perceive it to reward something other than good research". He feels that the data point towards a thin ice shell but that political powers have marginalized this interpretation and those scientists who advocate it. When discussing his own work, Greenberg generously bestows much credit on his former students, postdocs and colleagues.

In Unmasking Europa, Greenberg succeeds in conveying a story, not of heroes and villains, but about the rise and fall of ideas and how some become accepted for reasons that perhaps go beyond empirical support. In Greenberg's earlier work, Europa the Ocean Moon (Springer, 2005), which is of similar scope but targeted to a research audience, the political storyline is not particularly appropriate. In his latest work, he delivers an accessible and well-laid-out popular-science treatment in which the political narrative is more pertinent, although obviously biased towards his own perspective. Greenberg uses humour to balance out the tone, as in his suggestion that the reader should buy a second copy of the
Europa's fractured icy surface could conceal life beneath.

book just to cut out the images and do the geological reconstructions while reading the first copy.

Tides are the recurring theme of Greenberg's treatment - they "connect the orbits of Jupiter's moons to the geology of Europa, creating environments potentially suitable for life". Only one short chapter deals with the possibility of a biosphere; more detail on the known chemistry of Europa would have been welcomed. Nevertheless, his treatment of tidal dynamics is thorough.

Europa has not yet revealed a smoking gun, as have the icy plumes of Enceladus, to indicate that it is geologically active today. This has left the planetary geology community staring at the limited imagery of Europa, wondering what its surface features reveal about the interior.
Centuries ago, geologists I began adopting the uniformitarian mantra of 'the present being the key to the past'. In the ebb and flow $\frac{y}{z}$ of planetary science, with data streams punctuated by missions that are all too rare, we often find ourselves struggling to decipher the geological present, much less the past.

Unmasking Europa provides a comprehensive and engaging account of Europa's past and present, and sets the stage for the many questions that will be answered by future missions as we continue our search for life beyond Earth.

Kevin P. Hand is a scientist at NASA's Jet Propulsion Laboratory, California Institute of Technology, 4800 Oak Grove Drive, Pasadena, California 91109, USA.

e-mail:khand@jpl.nasa.gov

\section{Scripting scientists' lives}

\section{Leave a Light On \\ Ensemble Studio Theatre, New York City 22 January 2009. Part of the First Light Festival, which runs until March 2009}

Last year, at a first reading of her play about the life of biologist Robert Trivers, Ann Marie Healy noticed a stranger in the back of the theatre, laughing. Afterwards, the man strode over to the actor who had played the young biologist as a foul-mouthed and promiscuous genius working out the evolutionary logic of human kindness and conflict, and said: "You got it exactly right." That stranger was Trivers.

Healy's play features in New York's First Light Festival, a collaboration between the Ensemble Studio Theatre and the Alfred P. Sloan Foundation that incubates science-based theatre. The festival, which has run annually for more than a decade, includes nine full-length plays this year and continues until the end of March.

In Leave a Light On, Trivers is portrayed as an ambitious, untenured professor who ruffles feathers at Harvard University's department of zoology as he attempts to take a Darwinian approach to human nature. Dissatisfied with an academic culture that is hostile to his ideas, Trivers retreats to Jamaica to study lizards and then moves to teach at the University of California, Santa Cruz, where he meets Huey
Newton, former leader of the Black Panther party. Widely believed to have dropped 'off the grid', Trivers returns to academia more than a decade later to study the adaptive value of self-deception.

Healy weaves in the science with a light touch. In the play, with the help of a female colleague who is also a love interest, Trivers works out his theory of reciprocal altruism using a series of imaginary birds with distinct approaches to selfless behaviour: Suckers, who always groom their peers; Cheaters, who never do; and Grudgers, who only groom tit-for-tat. As in Tom Stoppard's play Arcadia, the script darts between centuries and characters, punctuating Trivers's sobering career with farcical episodes from the courtship of Charles and Emma Darwin that are meant to explain the logic of gene competition.

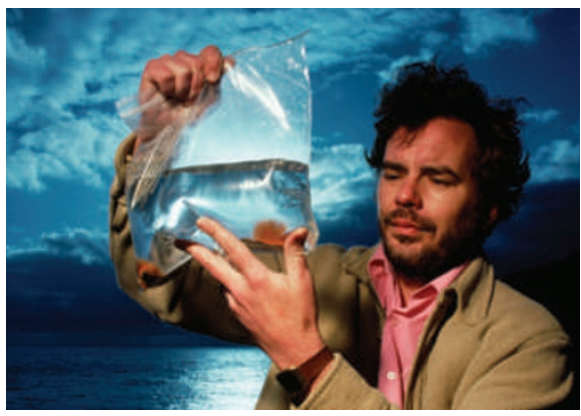

Robert Trivers's ideas on behaviour caused conflict.
The play hardly needs such asides: Trivers's own ideas are enough to drive the plot.

The 2009 First Light Festival began with an uneven selection of one-act plays collectively called $E=m c^{\text {brunch }}$, portraying a chemist discovering her brother's meth lab, an Olympic gymnast trying to prove her rivals are underage, and a mathematician confronting risk in an airport restaurant. The full-length plays take on an equally wide range of topics. Anna Ziegler's Photograph 51 portrays the familiar story of biophysicist Rosalind Franklin, whose X-ray diffraction images led the way to the discovery of DNA structure in 1953. Tommy Smith's Beautiful Night will show Soviet inventor and electronic-music pioneer Léon Theremin falling in love with a black ballerina in New York City in the 1930s - with live accompaniment from the eerie-sounding theremin instrument. And in the improbable monologue Five Easy Steps to Metaphysical Fitness: They Actually Work, comedian Emily Levine will impart wisdom gained by staging a one-woman show about physics while struggling with her pituitary-gland disorder.

"The goal is not just to demystify science but to show its intrinsic appeal, both emotional and intellectual," says Darcy Kelley, a neurobiologist at Columbia University and an adviser to the theatre. "Then science itself becomes a character, not just window dressing."

Jascha Hoffman is a writer based in New York. e-mail: jascha@jaschahoffman.com

See http://tinyurl.com/7otvba for more details on the First Light Festival. 